\title{
Microscopy in Forensic Science
}

Benjamin J Jones

This is the Author's Accepted Manuscript of the book chapter:

Jones, B.J. (2019) Microscopy in Forensic Science, in Spence, J.C.H. and Hawkes, P. (eds.) Springer Handbook of Microscopy. Springer, Heidelberg.

The final publication is available at Springer from: https://www.springer.com/us/book/9783030000684 


\section{Microscopy in Forensic Science in The Springer Handbook of Microscopy}

\section{Benjamin J Jones}

This chapter examines the use of electron microscopy, atomic force microscopy and other analytical techniques in forensic investigation and research. These tools can be used to enhance examination of human remains and trace evidence to improve understanding of cause of death, victim identification or post mortem interval.

A police-designed scenario is used to highlight trace evidence such as glass, gun shot residue and paint. The validity of forensic techniques is discussed, with reference to international standards, repeatability, and false convictions. Ballistic evidence is used to highlight the complexities in evidence interpretation, including manufacturing variability, environmental effects and likelihood ratios.

The use of SEM, AFM and other techniques in the development of forensic research is showcased, with particular examples from the field of fingerprints. Examples include improvements in the development of fingermarks from difficult surfaces, interaction of evidence types, and added intelligence from the crime scene, such as forensic timeline or gender of perpetrator.

Keywords: Forensic Science; Microscopy; Trace Evidence; Scene of Crime; Gun Shot Residue; Fingerprints 


\section{Forensic Microscopy}

\section{Introduction}

At a suspected crime scene police officers, scene of crime officers (SOCOs), or crime scene investigators (CSI) may seek evidence of a crime being committed, cause of death, evidence of involvement, identification of victim, evidence of third party involvement, and identification of victims and third parties. Advanced microscopy techniques can aid these forensic science investigations across a wide range of disciplines.

Evidence of the time since death, the post-mortem interval (PMI), can be of crucial significance. This can be estimated from macro observations, however, electron microscopy can aid examination of the body providing better PMI estimation, for example in study of morphological alterations in human nerves [1] revealing multiple stages of myelin degradation. PMI can also be estimated from colonisation of the body from insects such as blowflies. The stage of development of immature insects can provide evidence of the time of colonisation, and potential time of death. The examination and age estimation can be improved through electron microscopy examination of the morphology of the instar stages [2]. The developmental period, adjusted for temperature is species dependent and SEM can aid identification of closely related species, for example through ultramicroscopic examination of male genitalia of blowflies [3].

Understanding of the cause of death can also be aided by electron microscopy and computed tomography analysis. Examples of recent suggested developments in the field include TEM analysis of ultrastructural changes in the myocardium [4]; study of skin morphology and metallization in suspected cases of electrocution [5,6], analysis of toolmarks on bones leading to identification of type of knife, arrow head, or bullet as well as distance or forcefulness of attack $[7,8]$. Low vacuum SEM techniques to reveal the use of glass as a weapon or other microtraces of residues in bone [9,10], and modifications of scanning electron microscopy with microwave digestion suggest potential to lead to improvements in classification of drownings [11].

Separate from any human remains, other evidence of involvement is importance. Trace evidence, where analysis can be improved by electron microscopy includes glass, soil and gun shot residues [12-16]. As manufacturing methods improve and become more uniform, advances in microscopic analysis are required to identify evidence, and distinguish class and individual characteristics $[17,18]$. This chapter uses a police-developed scenario to examine the use of microscopy techniques for trace evidence from a crime scene.

\section{Forensic Science under siege}

Advanced microscopy is also highly relevant as a research tool for developing the field of forensic investigation, at a time when the validity of forensic science is undergoing extensive scrutiny. The following quote is attributed to the chief forensic pathologist for the New York State Police in 2009 [19], 
"So many innocent people get convicted based on junk science"

This can mean the technique may not always be appropriate, or the interpretation of the significance of the evidence is lacking, or there is insufficient scientific backing for the evidence. Several high profile cases where convictions have been quashed after many years due to re-examination of use or presentation of the forensic evidence. This might be Gun Shot Residue in the case of Barry George, convicted of the murder of TV presenter Jill Dando on the strength of one particle identified as GSR, before having his conviction quashed [3] or bite mark evidence in the case of Keith Allen Harward, who spent 33 years in jail before being freed on the strength of DNA evidence [20]. Analysis of data from USA from 1989 to 2017 shows over 490 people were convicted and later exonerated due to "false or misleading forensic evidence", after collectively serving over 5000 years in prison [21]. Much of forensic investigative or analysis techniques have been built up from practitioner experience, finding a method which works in one case and utilising this in future cases. In 2013 the National Commission on Forensic Science was set up by the Department of Justice and National Institute of Science and Technology in the USA in order to improve the reliability of forensic science. The founding statement $[22,23]$ sets the scene,

"Good Science for Good Justice"

This drive to improve validity and confidence in forensic science is echoed across jurisdictions and includes quality assurance, recommendation of protocols for seizure through to analysis [23], this includes practitioner accreditation and operation of laboratories with audited operating procedures and quality control, within an ISO17025 accreditation. The UK Forensic Science Regulator highlighted in 2010 that research and peer-reviewed publications are a cornerstone in ensuring both quality and confidence in forensic science [24]. Advanced microscopy plays an important role in this, through a critical analysis of processes, developing laboratory techniques, and increasing understanding behind the systems of techniques and their validity and limitations [25]. Identification of any third parties at a crime scene can be through DNA or fingermarks, for example. Here electron microscopy can aid research and development into novel techniques for improvements in sensitivity or detection rates [26,27]. In addition to trace evidence assessment, this chapter examines microscopy techniques and their part in research and development in the field of forensic science, with a particular emphasis on developments in fingerprint investigations. 


\section{Trace Evidence}

Crime Scene Investigation in fiction uses an array of technology to link a suspect with a crime scene. From Sherlock Holmes onwards the stereotypical investigator is equipped with a magnifying glass to hunt for clues. How much of this is based in fact? Consider the following scenario.

\section{Scenario 1.}

A man enters a bank, pulls out a gun and immediately fires at the ceiling, before pointing the gun at customers and staff, continually shouting commands for them to stand back. He fires again at the glass screen protecting the teller, the screen shatters and he leaps onto the counter and through the broken glass and helps himself to cash from the open teller positions, thrusting rolls of notes into a holdall. One customer tries to surreptitiously call police on his mobile, but spotting this the robber leaps back over the counter, manhandles and pistol whips the witness and grabs his phone, before rushing out of the bank and driving off, knocking into some dustbins on the kerb as he does so. The witness's phone is found a few metres down the road, and a suspect car is found left abandoned several miles distant at a road junction.

Maybe the first evidence to think about is CCTV footage, or serial numbers on the banknotes. However, Locard's exchange principle, often paraphrased to "every contact leaves a trace" suggests there is potential evidence transferred from the suspect to the scene and from the scene to the suspect [28]. The gun is fired, leaving firearms discharge residue (FDR). The glass is shattered and may be deposited on the suspect's clothes or shoes, or later transferred there following movement around the scene. There may be a footwear mark on the counter where the robber stood, perhaps some fibres from his clothing have been caught as he moved through the broken window. There could be fingerprints either at the bank scene or on the phone, gun or car. Maybe some blood has spattered from the pistol whipped witness onto the robber's clothing. Possibly some paint from the car has been left at the site on the dustbins collided with in the getaway. The car is also a crime scene, if a suspect is found the prosecution will hypothesise that the man was at the bank, fired a gun and was in the car. Trace evidence, such as the blood, fibres, glass and discharge residue we have identified, may be transferred from the bank to the suspect and from the suspect to the car.

The following sections will examine the role of microscopy techniques such as scanning electron microscopy and atomic force microscopy in forensic trace evidence examination based around this scenario. 


\section{Gun Shot Residue (GSR)}

When a firearm is discharged, as in our scenario, the firing pin impacts the primer cap on the back of the cartridge, the primer ignites and sparks the main propellant and the bullet is forced out of the cartridge and down the barrel of the gun. With the bullet exiting the weapon is a plume of gaseous and fine particulate matter, which will comprise of residues of the primer and propellant and material lost from the bullet and the barrel as the bullet traverses. We refer to this as Gun Shot Residue (GSR) throughout this section, other works also use the term Firearms Discharge Residue (FDR), which might also be thought of as a more general term.

GSR material typically consists of spherical particles of approximate diameter a few hundred nanometres to a few microns $[12,13,29]$. The chemical composition is rich in nitrates from the propellant, transition metals such as copper and zinc from the cartridge case, and heavy metals such as lead, antimony and barium from the primer.

Early methods for detection used colour change reagents to identify GSR: the Griess test for nitrites, and sodium rhodizonate for lead. However, these tests are not specific to GSR and cannot identify multiple elements within the individual particles. Scanning electron microscopy with energy dispersive $x$-ray spectroscopy (SEM-EDX) allows identification both of the characteristic shape of the GSR particles and the elemental composition of individual particles. An identification system developed in 1970s [12] described a particle as unique for GSR if it contained all three of lead, barium and antimony, particles with two of these metals were said to be indicative of GSR. Figure 1 shows a typical example of the SEM image and corresponding EDX spectrum of a GSR particle.

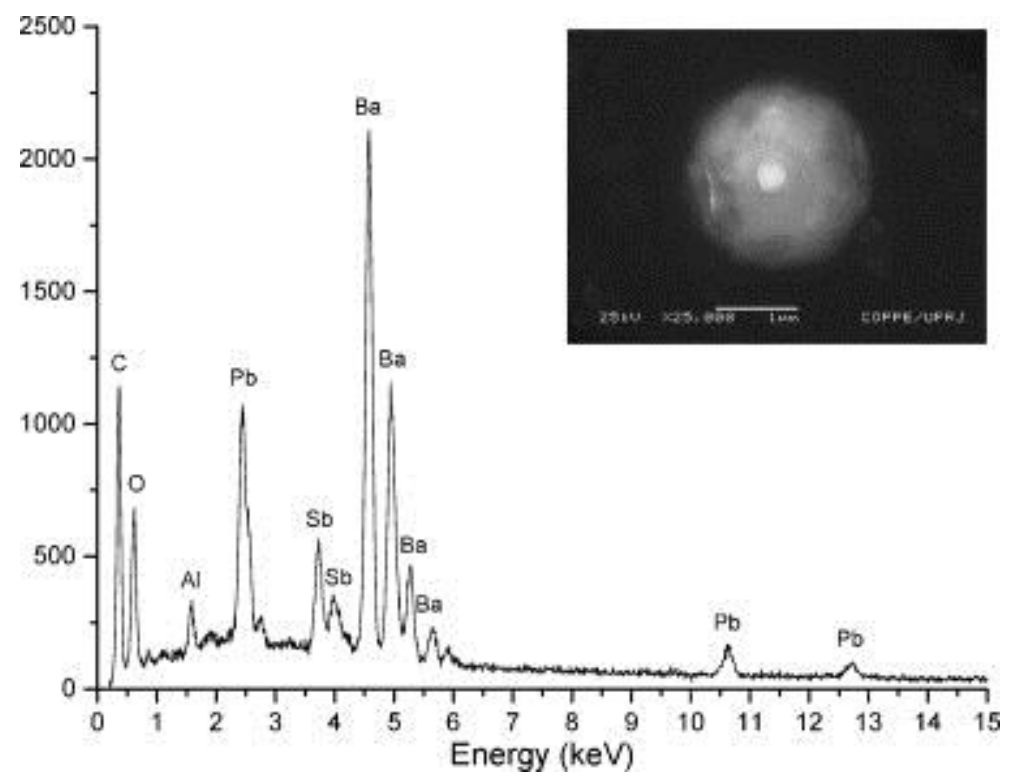

Figure 1 typical SEM image and EDX spectrum of a standard GSR particle, showing the spherical shape and lead, antimony and barium in the composition [29]. 
The superiority of SEM-EDX for detecting gun-shot residue is shown in [30] where over 8 samples SEM-EDX identified 447 particles, sodium rhodizonate identified 11. Electron microscopy is now the standard technique for GSR analysis, however, rhodizonate continues to have potential to aid in crime scene investigation with ballistic evidence, used as a histopathological stain to highlight position of GSR to aid interpretation of wound evidence, linking to the range of shooting [31].

Candidate material from a suspect's skin can be collected for analysis with pressure sensitive adhesive, gel lift or a carbon-loaded adhesive directly on a SEM stub. The adhesive or stub can be repeatedly pressed onto areas of interest, for example the back of a shooters hand and thumb. Detection depends on the efficiency of collection and number of particles deposited or remaining on the skin. This varies significantly, depending on the ammunition and weapon used, from shot to shot of a single gun, and depending on the action of the shooter after firing. Reports of initial number of deposited particles vary from 0 to over 3000 particles on the shooters hand $[30,32,33]$. GSR has a low persistence on skin, the average loss is reported as broadly a factor of ten after one hour and a factor of 100 after 10 hours [12]. However, this too is highly variable, in one test the number of particles present after six hours is $20 \%$ of that immediately after firing, others show zero particles two hours from firing $[30,32,33]$.

However, in addition to presence on skin, GSR particles can be deposited directly onto fabrics or transfer onto items of clothing. In these circumstances some particles may become trapped in fibres and may persist significantly longer than the periods outlined for GSR on skin. The duration that particles will remain present will depend on the material type, the location of particle entrapment, such as pocket, stitching or cuff, and activity since transfer [32].

In GSR analysis the chemistry, morphology and the pattern of distribution of particles deposited can provide information to the investigator, over and above the identification of the material as GSR. This may be to find the weapon type, the shooting distance, or help clarify if the source is due to firing a weapon or contamination. In general, the further the distance between shooter and target, the wider and more diffuse the area of GSR. Molina et al. [34] used SEM-EDX to study the pattern GSR on the hands of a series of undisputed suicides and identified a spatial distribution in $18 \%$ of cases that identified how the weapon was held. The organic chemistry of the particles, highlighted by Fourier Transform Infrared Spectroscopy $[35,36]$ or morphology and surface structure of particles by AFM [36] may also provide some information on the distance of the firer from victim. However, as with all powder or particulate based materials there is a danger of instrumental effects with particles adhering to the probe, or moving during imaging [37].

An air sampling study [30] shows 750 GSR particles per cubic metre the in area around a shooter immediately after firing 10 shots. This gives some indication of the number of particles available for deposition on shooter or victim outside of the initial direct plume, but also highlights the possibility that bystanders as well as the shooter or target may have GSR present on their skin and clothing. Although this figure should be taken against a backdrop of a few thousand particles per litre ambient particulate pollution, the importance of the release of GSR particles away from shooter and target is further demonstrated by a study of 30 bystanders to a shooting [33] where 17 were found to have detectable GSR on their right 
hand, and $30 \%$ retained detectable particles 2 hours after the shooting, similar to that observed on the shooters [33]. There is further potential for adventitious contamination, even of 'unique' identifier particles, metal workers, brake mechanics, and electricians have been identified as possible occupations that may produce metal particles on the hands [12]. There are also other possible causes of environmental contamination, for example, from increased levels of particulate matter and trace elements including $\mathrm{Sr}, \mathrm{Sb}, \mathrm{Ba}, \mathrm{Pb}$ after firework displays [38]. Therefore the three metal $\mathrm{Pb}, \mathrm{Sb}$, Ba particles may be better described as 'characteristic' of GSR, rather than 'unique' and two metal as 'consistent' rather than 'indicative'.

The possibility of adventitious or environmental contamination, persistence of particles on skin and clothing and the variation of residue morphology and chemistry with ammunition type or distance from shooter, means that the interpretation of a particle as GSR and the relevance of this to the investigation is a non-trivial matter. This demonstrates the importance of evidence interpretation through understanding of the probability of finding particles of residue apparently similar to GSR from an innocent route. This is encapsulated in Bayesian interpretation [39] generating likelihood ratios for finding evidence given the prosecution hypothesis, against the defence version of events. Reinterpretation of the evidential value of a single particle of material characteristic of GSR found in a coat pocket led to the quashing of the conviction of Barry George for the murder of Jill Dando.

Lead-free primers also exist, in so called 'non-toxic' or 'heavy-metal free' (HMF) ammunition, in these cases a number of other elemental traces may be found, for example titanium, potassium or strontium from the primer $[13,29,40]$. For these particles the shape may also be more irregular than that of the standard lead-based primer. The chemistry and the shape affect the use of SEM-EDX in the identification and analysis of GSR based evidence, with a wider range of particles that may be GSR, examples are shown in figure 2. With no characteristic shape or chemical signature, the identification of particles as GSR becomes more problematic. For these ammunition types analysis of the internal microstructure of the suspected GSR particles may become significant [18] through higher resolution backscattered imaging for distribution of elements within particles. Combining SEM-EDX and EBSD analysis to study nanocrystalline domains, characteristic of high temperature and subsequent rapid cooling, would perhaps provide high specificity for gunshot and explosive residue, however this remains a technological challenge at the required resolution [18].

In some cases gallium or gadolinium can be added as an artificial taggant to the primer, the range of primers and taggants used though could aid in the use of GSR analysis to provide more intelligence about the crime scene, identifying the type of ammunition used. Some research shows use of fluorescent lanthanide taggants in the ammunition can aid both identification of GSR through SEM-EDX and aid initial screening for gunshot residue at a crime scene by use of monochromated light sources and viewing filters. 

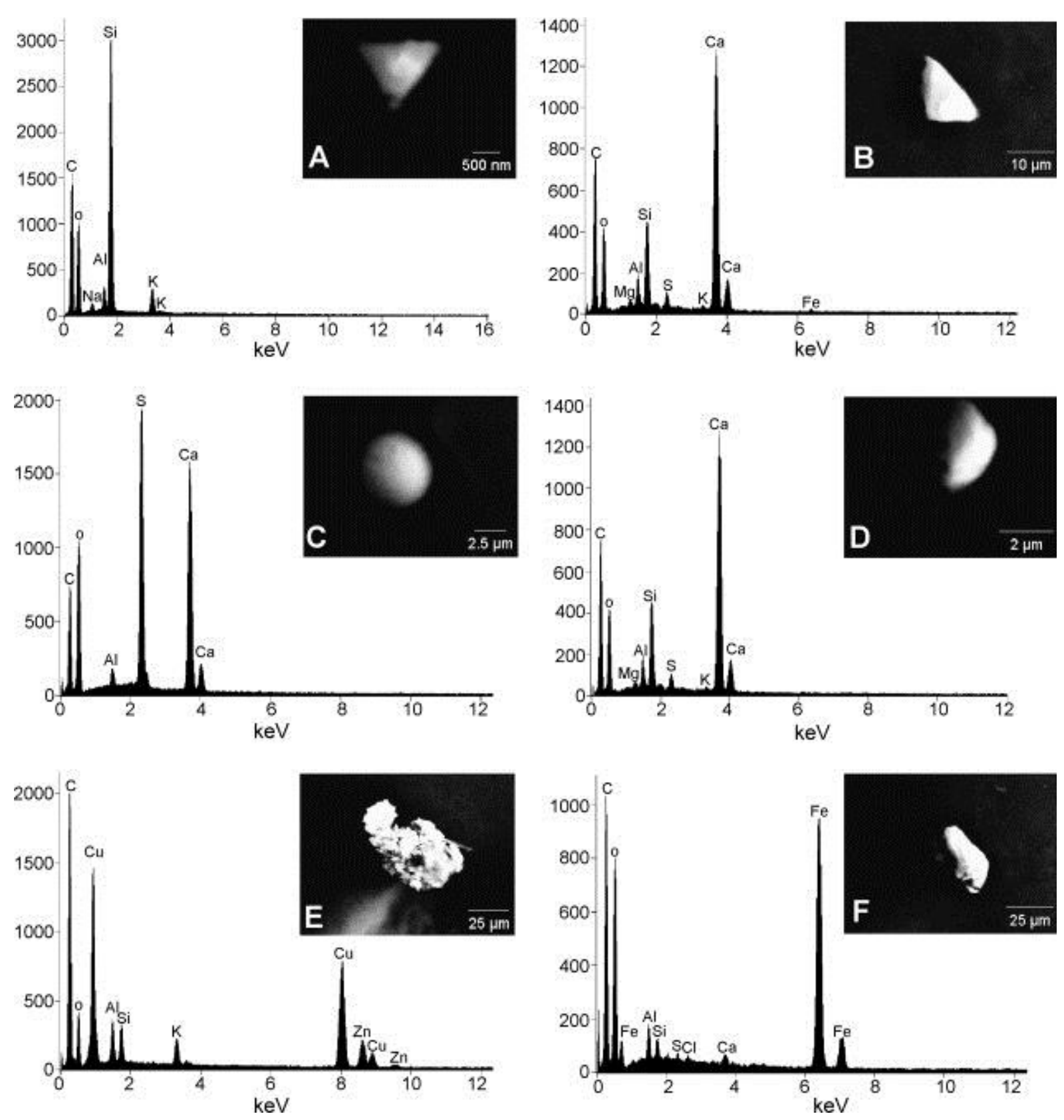

Figure 2. Examples of GSR particles from non-toxic ammunition, from a single Brazilian supplier. The range of particle sizes, shapes and compositions is significantly greater than for standard ammunition [29].

Trace evidence analysis of gunshot residue is not the only ballistics evidence to utilise microscopy, the study of striations on recovered bullets, firing pin marks on primer caps, ejection marks aids the link between a specific weapon and the bullets or gun cartridges found at crime scenes. Light microscopy can show striations caused by the passage of a bullet though a rifled barrel. The angle and spacing of the marks are class characteristics linking the bullet to the type or brand of weapon and the individual striations may help 
identify the individual weapon. This is part of a wider area of forensic metallurgy, where changes in microstructure due to stamped impressions can be utilised to recover erased marks, through etching or EBSD; analysis of car headlamp filaments can determine if they were on at the time of a crash, and fracture surface analysis [41-43] can help distinguish between manufacturing defect, sabotage or terrorist attack.

\section{Glass and Paint}

Glass appears in a large range of crime scenes, particularly road traffic accidents and house breakings.

Glass is comprised of fused silica with added elements such as calcium and sodium, to aid processing and machining, or to improve the properties of the finished product. Float glass, the sort of plate glass in window panes, as opposed to container glass, such as wine bottles, is formed by floating the molten glass on a bed of liquid tin. This allows a flat surface and even thickness to be produced. Some tin is incorporated into the glass on the near float surface. Other materials may be incorporated into glass, such as boron for heat resistant glass such as car headlamps, lead in lead-crystal tableware, iron in window glass for better heat insulation, and trace elements such as titanium and potassium. Annealing processes and lamination also affect the properties of the glass product, its strength and the way it breaks [16].

In a forensic investigation glass found on a suspect will be compared with that from a control from the crime scene. In our scenario the control will be a sample of the remaining glass in the window of the teller, may be compared to glass found in the car or on any suspect. Analysis of any large pieces may be possible by a physical fit of the broken glass pieces to each other. This will be unlikely in a scenario where we are looking at recovering small fragments of glass from a suspect's clothing. The first approach may be to analyse the refractive index of the glass. Glass from different manufacturers, processes and with different compositions will have different refractive indices, and the analysis of these is now a standard forensic laboratory technique. Recovering glass pieces from for example a suspect's clothing, may lead to finding glass fragments from multiple sources. The refractive indices (RI) measurements will allow an initial statistical grouping of the recovered pieces. However, due to standardisation of manufacturing processes there is not as much variation in $\mathrm{RI}$ as once noted. Determination of $\mathrm{Rl}$ is regarded as a quick exclusion test rather than being meaningful when the control and recovered samples appear to match. Glass fragments that cannot be excluded by $\mathrm{RI}$ analysis can be examined by SEM-EDX or ICP-MS to examine levels of trace or minor elements in the fragments.

A source level analysis concerning the measurements and uncertainties of refractive index and elemental composition of the sample and control can in a Bayesian examination be paired with information on the frequency of occurrence of similar glass fragments, possibly 
from a contemporary database, to provide an indication of the likelihood that the sample and control come from the same source. Similarly to the GSR analysis in previous section the transfer and persistence of other trace evidence is also important and this may enable an activity level analysis to be conducted, how likely is it any glass found was caused by the suspect shooting the window. This will need to examine factors such as how many fragments are likely to be deposited on the shooter when firing at glass from that distance, how likely is his clothing to retain them, what are the effects of his actions since then on the number of fragments retained, and how likely are any other actions such as his employment to result in glass fragment transfer. Whilst likely to have improved evidential value it is not always possible to conduct activity level analyses.

Paint, which might be from a single car as in our scenario, a road traffic accident, or a painted window frame in a house breaking or burglary, can also be aided by investigation by SEM-EDX. Rather than a single layer of colour, painted surfaces are often formed of multiple layers, undercoat, primer, lacquers and top layer. A silver 1997 Ford will have a different paint structure to a silver 2017 Ford, which in turn is different from a 2017 Fiat, even if they appear the same colour on the car or on initial inspection of the paint flake.

In our scenario the paint transferred from the car as the suspect fled from the scene can be examined; however, a glancing, sliding blow may have just removed the top layer and evidential value will be limited. If a fragment is available, however, a thin sliver from a flake of paint can be examined under a light microscope to visualise the individual layers thickness and colours. If this is suggestive of a match, further analysis can include Fourier transform infrared (FTIR) microspectroscopy, to determine the organic constituents of the individual layers. SEM-EDX can be used to examine the inorganic pigments. The ratio of components within each of the layers can be compared to database information, or a similar analysis of a control or second crime scene sample.

As the number of layers with matching pigment increases, the higher the evidential value. Nevertheless, there is only limited evidential weight that can be attached to layers of a standard factory finish paint. Vehicle re-sprays could be different but are difficult to generalise. The weight of the evidence would be of greater value if working at the activity level rather than source level, and two-way transfer can increase the value of the evidence. The Bayesian analysis enables combination of probabilities to assess the likelihood of finding multiple components of evidence in a given scenario.

\section{Other trace evidence types}

Gunshot residue, glass and paint fragments are not the only trace evidence types, other items can be treated in a similar manner. Hairs and fibres can be transferred from victim to suspect and vice versa [44], in our scenario the perpetrator grapples with one of the bank customers, which could lead to transfer of trace evidence. Figure 3 shows the structure of a hair fragment, revealed by AFM. Parameterisation of the structures revealed can lead to information to match with a suspect hair, or to provide additional intelligence on ethnicity, dyeing and heat treatment, to build a profile of an unknown suspect. Pollen, sand and soil $[14,15,45]$ can be examined through mineralogy, surface structure, organic content and microbial DNA profiling. This can lead not only to evidence recovery from victim-suspect 
transfer, but help build up a narrative of events describing an incident. Soil evidence of this type was crucial in the 2014 re-examination of the 1977 World's End murder of two teenage girls in Scotland [45].
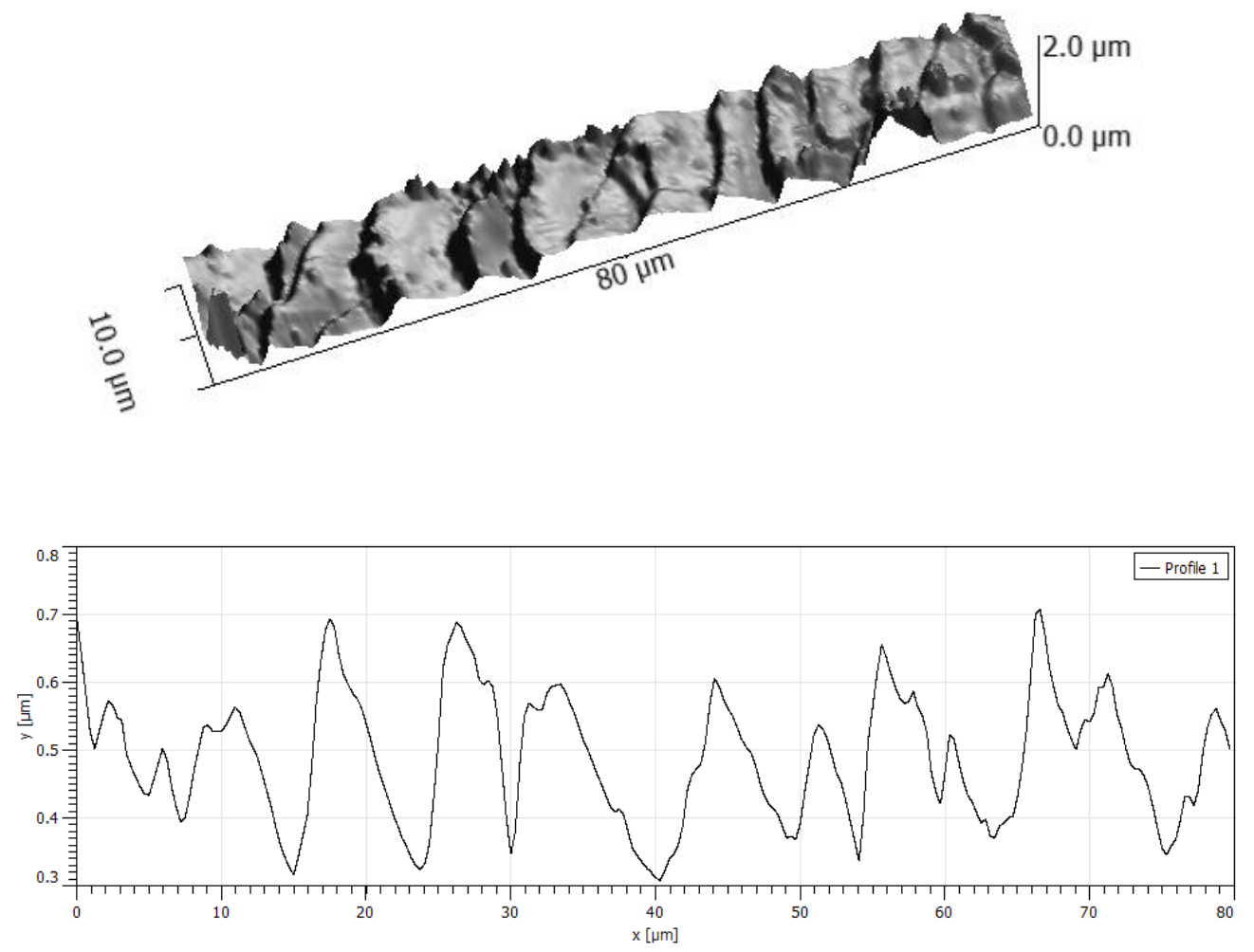

Figure 3, AFM of hair structure provides additional information over light microscopy due to $3 \mathrm{D}$ quantification. As well as the structure of the hair surface which may aid determination of gender or ethnicity, damage due to colouring or other treatments can be detected. 


\section{Fingerprints}

Fingerprints have been used for over a century to help identify criminals and victims and to link people to places where they have left their mark. This process matches fingerprints collected from suspects, for example from a full set of ten prints inked at police stations ('ten print' or 'fingerprints') to marks found at crime scenes ('latent fingerprints' or 'fingermarks').

Figure 4 shows a low magnification scanning electron microscopy image of a section of a latent fingerprint [46]. The general flow of the ridges form recognisable shapes, here the ridges form a loop pattern, other marks can be a whorl or arch. Such patterns, the so called first level detail, can be the basis of immediate exclusion of a match, demonstrating that two marks do not come from the same finger. However, it is the disruptions to the overall pattern: the ridge endings and bifurcations that allow a mark to be identified. This second level detail is annotated $A$ and $B$ for ridge ending and bifurcation respectively in Figure 4 . A dot, effectively a very short ridge, can be thought of as two ridge endings back to back. Similarly other combinations of bifurcations and ridge endings form other features, such as two bifurcations forming a lake, C. The presence of these minutiae, or 'Galton details' after Sir Francis Galton, as well as their position and combination form the basis of modern fingerprint matching.

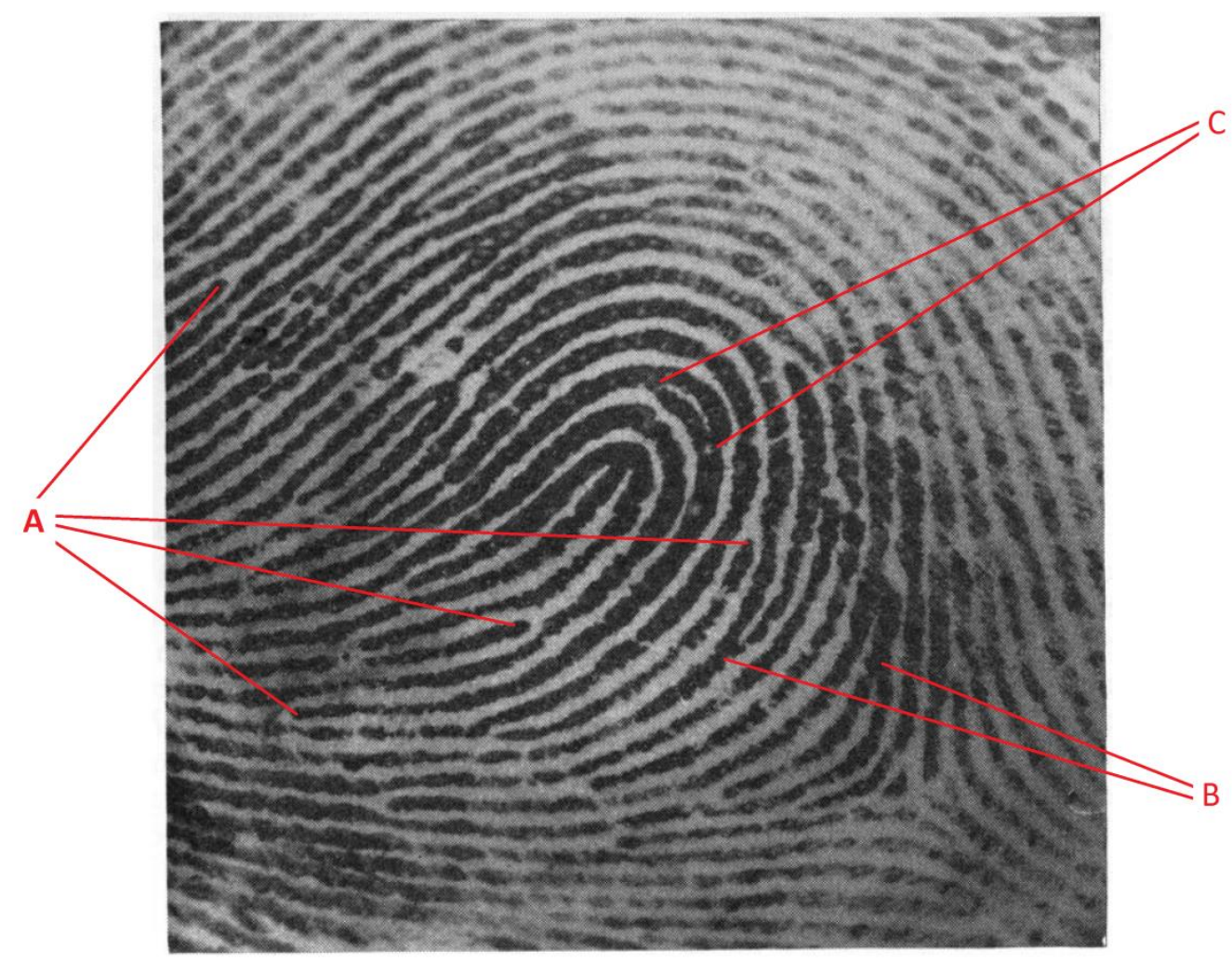

Figure 4 Early demonstration of SEM imaging of latent fingerprints. The mark is imaged when ten days old, on glass, coated with a thin layer of gold. The distortion at the edges is due to the low magnification. Galton details are annotated as $(A)$ 
ridge endings, $(\mathrm{B})$ bifurcations and $(\mathrm{C})$ back-to-back bifurcations forming a lake or enclosure. [46]

The width of a fingerprint ridge, and therefore the size of the second level detail, is approximately 200 microns, where better clarity and resolution are possible third level detail, the ridge edge structure and the position of the pores can also be used to aid identification.

\section{Development of visualisation techniques}

Fingermarks comprise between $20 \%$ and $98 \%$ water, with other components including salts, fats and amino acids $[47,48]$. In general, Scanning Electron Microscopy in its standard form utilises a high vacuum, which may cause some water loss from a fingermark and be detrimental to its subsequent development [49]. However, variable pressure and environmental SEM may help negate this effect with reduced vacuum and no need to apply a thin conductive layer on the surface [50]. The Centre for Applied Science and Technology (CAST), part of the UK Home Office, issues the Fingerprint Visualisation Manual (and earlier editions as HOSDB or PSDB) which provides definitive guidelines as to the use and suitability of techniques for fingermark development. SEM is classified as a category $B$ process, not for initial use and may be partially destructive or detrimental to other analysis, however, may provide some useful information [51].

More commonly than use for visualisation of marks, SEM, AFM and TEM have been utilised for investigating techniques for fingermark visualisation, both in the research area expanding the science behind existing techniques, on in the exploration and development of novel processes.

Fine powder is a development method widely known and frequently used to visualize latent fingerprints. Common fingerprint powders consist of particles of aluminium, titanium dioxide or carbon. Scanning electron microscopy has been extensively used by the UK Home Office and other researchers in the characterisation of fingermark powders [51-53] These commonly use particles ranging in size from a few hundred nanometres to a few microns in diameter, the powders and the interaction between development agent and latent mark can be observed in a number of TEM and SEM based studies [53-56], an example is shown in figure 5 below. There is substantial research in the development of novel powders for fingermark visualisation, particularly for example fluorescent nanoparticles [57-60]
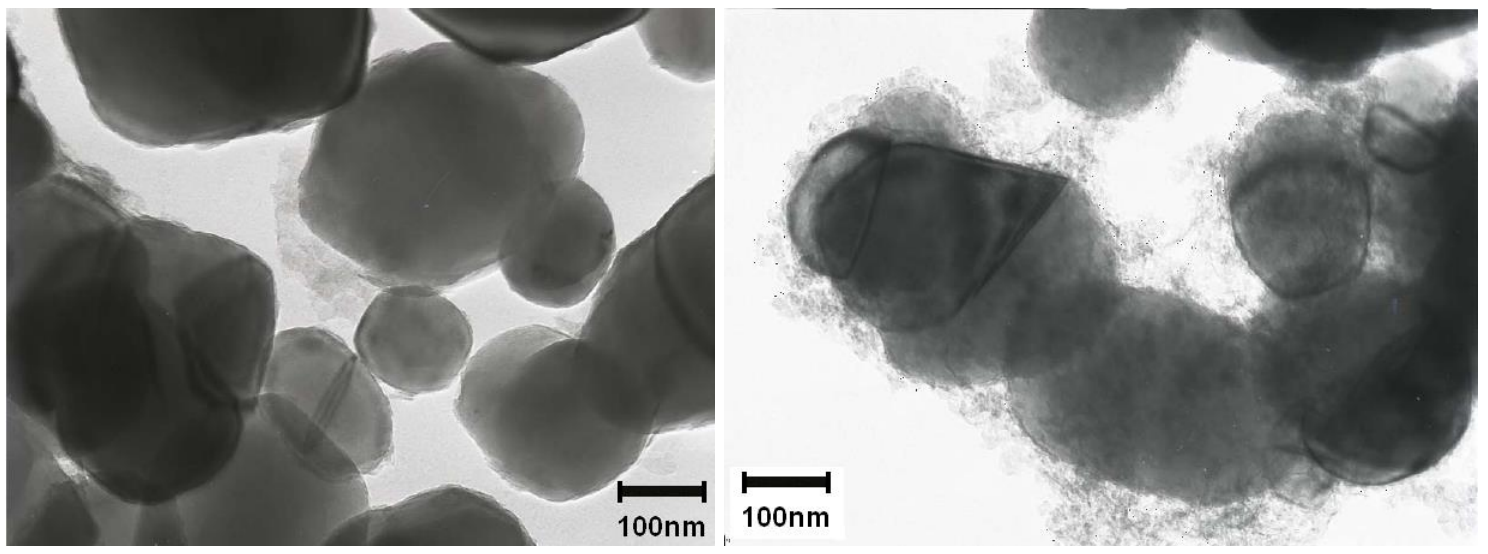

Figure 5 Comparison of morphology and surface structure of titanium oxide based fingerprint development powders [53] 
Techniques other than powders are sometimes optimum, depending on the surface and environmental conditions to which the mark has been exposed [51]. Electron microscopy has also provided useful images from fingermarks developed with techniques such as superglue, vacuum metal deposition, and physical developer. Techniques can also be applied in sequences in order to improve contrast or detection rates, and SEM can be utilised interactions of successive development processes or in cases where there are combinations of evidence, such as fingerprints in blood [50,54,61].

Figure 6 shows the zinc nanoparticulate decoration of polycyanoacrylate caused by a vacuum metal deposition process applied after superglue fuming. This process sequence is found to give good quality marks on fingermarks on polymer banknotes [62]. Other research examines development of polymer processes for latent fingerprint development [63]

(a)

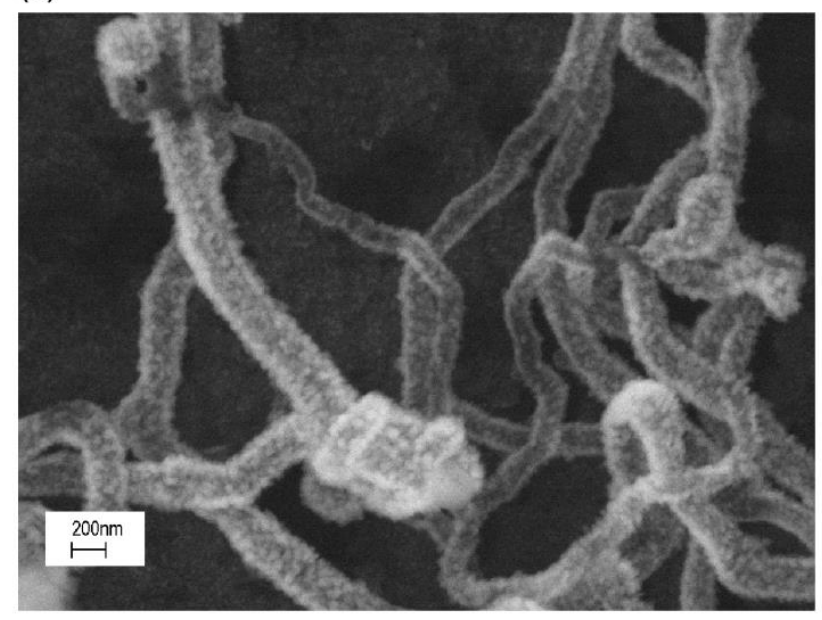

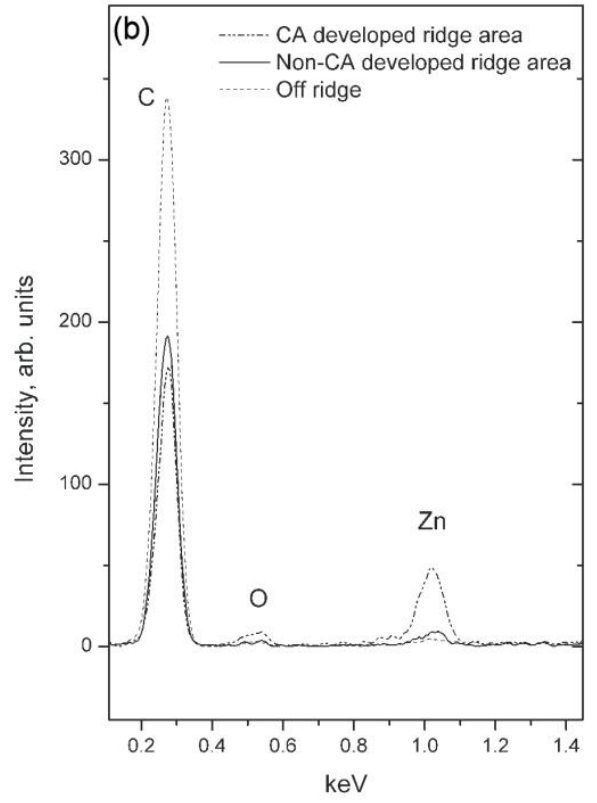

Figure $6 \mathrm{BEI}$ image and EDX spectra of fingermark development through cyanoacrylate and vacuum metal deposition, showing interaction between zinc and polymer [50]

\section{Fingermark - Surface Interaction}

The substrate on which a mark is deposited is very important in deciding the most appropriate visualization technique to use, and this is built into the CAST manual [51]. In our scenario, different techniques will be optimum for recovering marks from surfaces such as the phone, bag and recovered banknotes $[55,56,62,64]$. Electron and atomic force microscopy are invaluable tools for understanding the interactions between fingermarks and the surfaces onto which they are deposited $[55,56]$. 
AFM also helps characterise surface structure [56] of materials with potential fingermark deposits, and SEM to explore the behaviour of marks and development agents, showing the interaction between surface and agent, as well as mark and surface. Figure 7 shows an example with cyanoacrylate fuming affected by surface features; powder suspension development can also be strongly affected by varied texture of substrates [56].

The use of common black powder for fingerprint development on white and light coloured plastics can sometimes show high levels of background staining, reducing the contrast of the fingerprint or rendering evidence recovery impossible. Bacon et al. [55] used SEM with variable accelerating voltage to explain the apparently erratic distribution of carbon-based black fingerprint powder adhering to polymer surfaces away from areas of fingermark, illustrated in figure 8. At low voltages the carbon powder distribution was clearly observed; increasing the accelerating voltage and therefore the penetration depth showed the presence of titanium based pigments correlated with the location of the overlying carbon powder. The presence of titanium was observed in the majority of recovered light-coloured polymer samples and different development methods are now recommended for these types of samples.

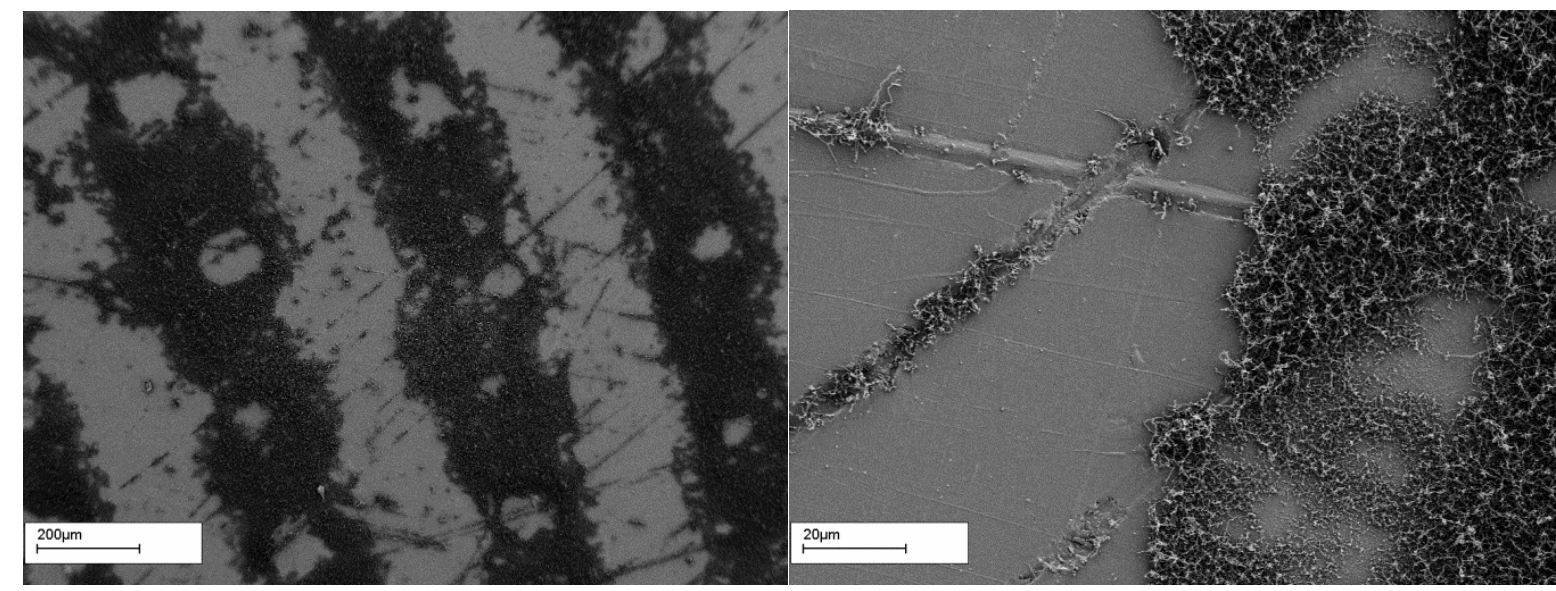

Figure 7 Effect of surface scratches on fingermark development by cyanoacrylate fuming 

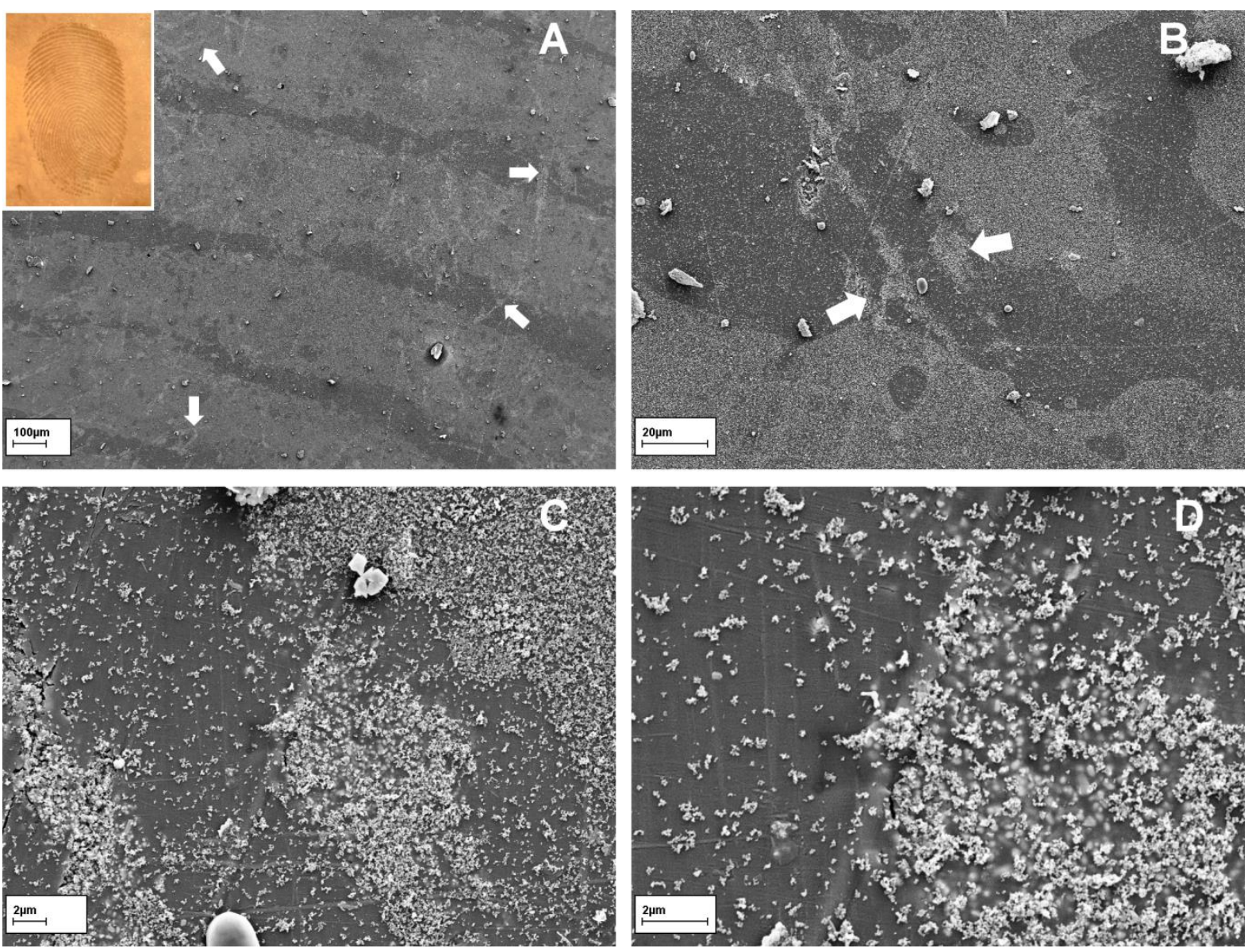

Figure 8 Effect of sub-surface titanium based pigment on the carbon powder development of fingerprints on polymers [55]

Goddard et al [65] also demonstrate the importance of surface interactions in fingerprint studies, using AFM to study surface corrosion processes caused by fingermarks on brass subjected to heat and humidity, particularly of relevance to handling of gun cartridges. This corrosion controlled mechanism also suggests the analysis is of relevance to fingermarks recovered from fire or underwater scenes.

Fingermarks on paper can be particularly complex. Paper is a porous structure and differences in fibres, binders, pigments and processing lead to large variation between the structures from different manufacturers, as shown by SEM in figure 9 . The porosity allows the fingermark deposit to be absorbed into the paper, in three dimensions, with the potential for differential aborption rates for the different chemical components of the mark. Powders for fingerprint development become substantially less effective, as the mark is effectively now sub-surface, amino acid reagents such as ninhydrin are routinely used. Nevertheless, AFM and SEM can provide some information particularly with aid to the identification of the chronology of documents. Kasas et al [65] use these techniques to identify ball-point pen ink above a layer of printing, Watson \& Watson [67] use AFM to explore ball point pen lines crossing each other, and overlapping fingermarks, though limit the substrate to smooth 
photographic paper or glass. Attard Montalto et al $[68,69]$ and Bailey et al $[69,70]$ use SEM to examine paper and printing structure, and identify ToF-SIMS as an analytical tool to assess whether printing is above or below a fingermark, by for example, the presence and distribution of sodium in the top surface of the document. The texture of the laser printed surface is shown in figure 9.

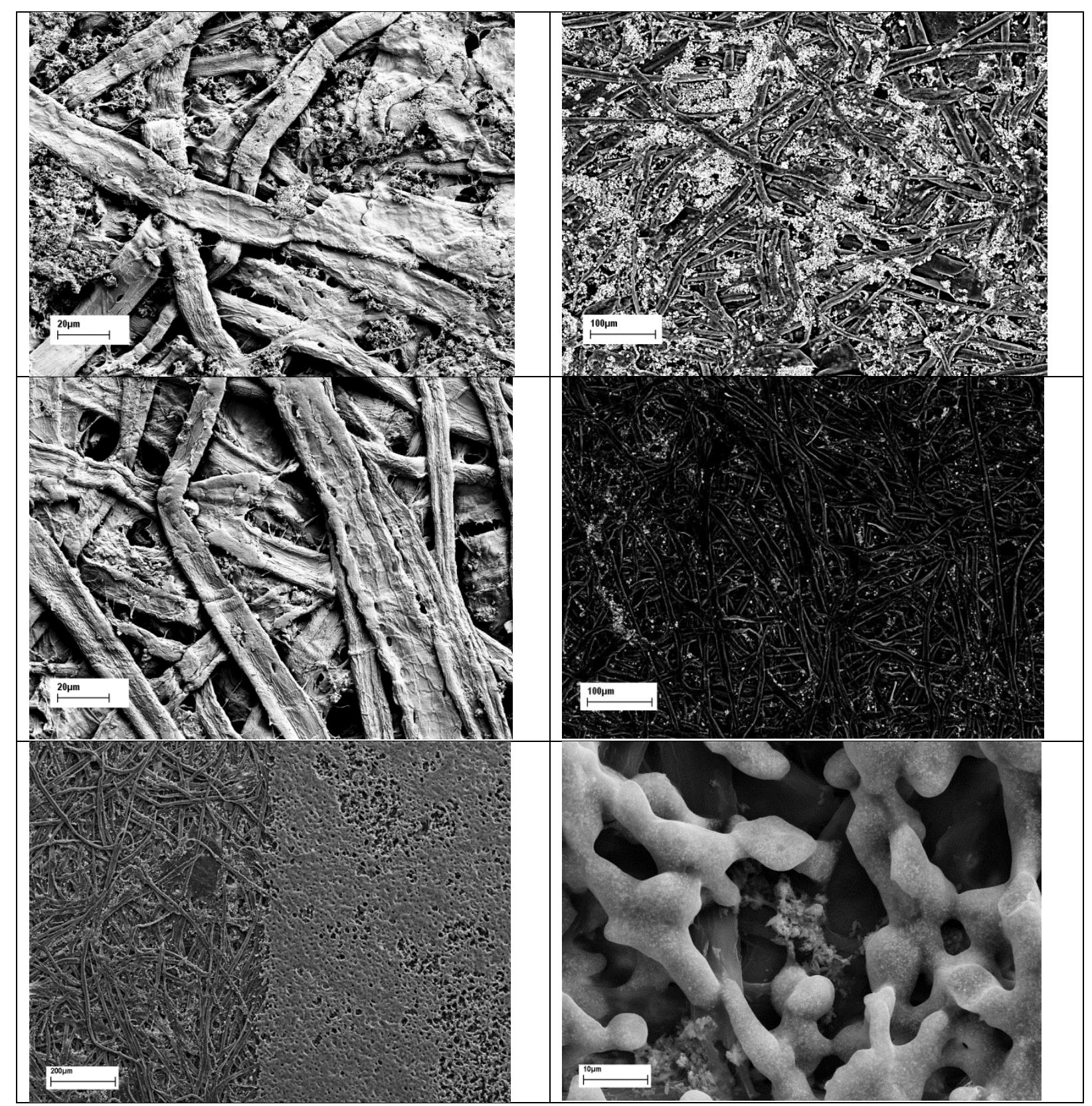

Figure 9, SEM Images of white papers, top row: secondary electron $(\mathrm{L})$ and backscattered electron imaging $(\mathrm{R})$ showing surface structure, porosity and distribution of pigment. Middle row: an alternative brand of paper showing dfiferences in pigment morphology and distribution as well as material porosity. Bottom row: paper with laser printing, boundary of a printed area $(\mathrm{L})$ and higher magnification of printed area $(\mathrm{R})$ showing structure, porosity and underlying paper fibre and pigment. 
The variation of paper structure, whilst having an adverse effect on the development of fingermarks and the harmonisation of mark development processes, may aid forensic investigation in providing a method for characterising source of documents.

\section{Fingermark composition variation}

The fingerprint deposit, contrary to the suggestion in figure 4, is not a homogenous, continuous material. Instead the mark consists of complex mixture of water, salts and amino acids, the chemistry of the mark is strongly dependent on the donor, diet, age, gender and recent behaviour of the donor, for example running fingers through their hair, wearing gloves, typing. SEM can reveal the interactions of development agents that are dependent on the marks chemistry. Figure 10 shows a fingermark developed with ethyl cyanoacrylate (superglue) where the deposit concentrates around the pores.

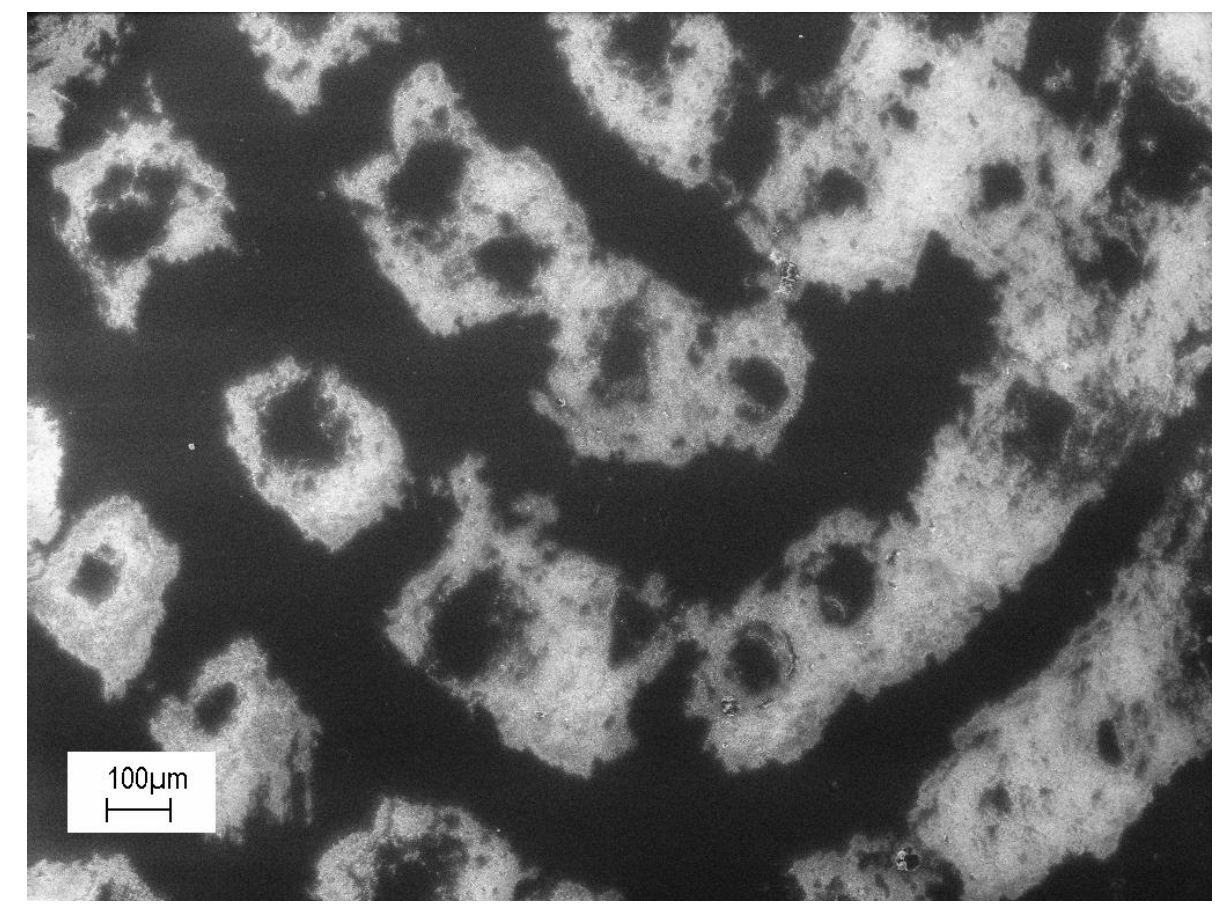

Figure 10: SEM image of fingermark developed with superglue, showing variation in effective polymerisation leading to 'dotty ridges' [50].

Recent projects have started to make use of this inter- and intra-donor variability to gather additional intelligence about the depositor of a fingermark, exploring techniques such as matrix assisted laser desorption of ions, Fourier transform infrared imaging, x-ray photoelectron spectroscopy or secondary ion mass spectrometry to explore variations in chemical composition and distribution within a fingermark $[71,72]$.

The chemistry of a latent mark is further complicated by exogenous materials that may be on a person's hand such as make-up, soap, or food residues, these can affect the deposited mark and its subsequent visualisation. However, exogenous compounds such as condom lubricants and drugs of abuse can lead to additional intelligence on the crime scene and can 
potentially be detected through microscopy and spectroscopy methods [71,73]. MALDI techniques have been developed for this purpose and incorporated into police intelligence gathering [74].

At a crime scene one of the key areas to identify is the forensic timeline. For fingerprints this can be difficult, if a print is found at our crime scene scenario was the suspect simply and legitimately in the bank as a customer last week, or is it the man potentially committing armed robbery? Dorakumbura et al [75] and Popov et al [76] use AFM to examine the shape of latent fingerprint ridge and its change with time, as shown in figure 11. In addition to height, adhesion and stiffness variation, both teams observe migration of material away from the main ridge over a period of time, either through topographical, adhesion or phase imaging [75,76]. Dorakumbura et al [75] utilise a glass microscope slide as a substrate and show variation over 28 days. Popov et al [76] use silicon as a model surface, but also demonstrate the effect on Formica surfaces over 61 days, with potential relevance to crime scene material. The spread of material a few nanometres thick $[75,76]$, change in adhesion properties [75] and the degradation of the revealed layer [76] may add additional intelligence on the mark donor [77], aid the identification of the age of the fingermark, and help to understand the behaviour of methods of development, particularly as nanostructured or nanoparticulate methods are further explored.
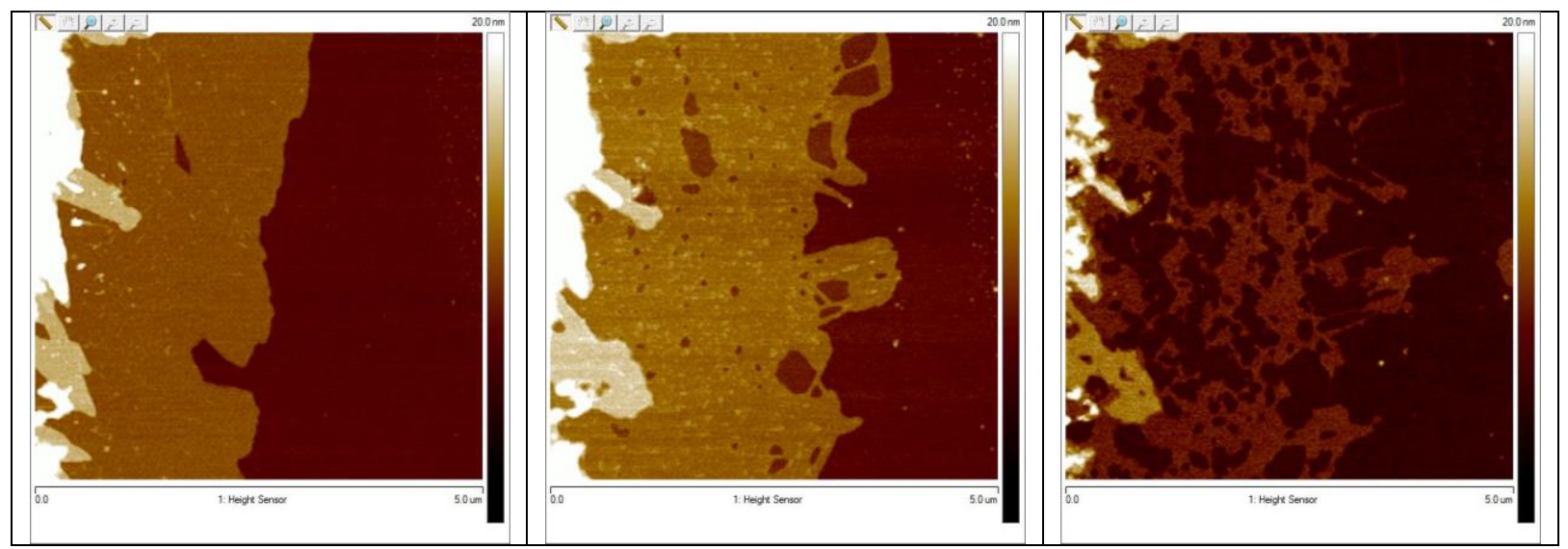

Figure 11 AFM topography map of edge of fingermark ridge, showing progression and degradation of a $4 \mathrm{~nm}$ thick layer from the edge of the main ridge at 1, 16 and 44 days from deposition [76]

Fingerprint science is one area of forensics making use of AFM, other examples range from physical hacking into credit cards or mobile phones with electronic modes of AFM [78,79], to distinguishing types of adhesive tape [80] or age of blood [81] with AFM adhesion measurements. 


\section{Conclusions}

In case work SEM-EDX is now a standard methodology to classify trace evidence such as glass fragments and identify gunshot residue. Advances in the analysis process are needed with the developing field, for example in heavy metal free ammunition, internal structure measurements of gunshot residue particles require crystal structure measurements for better identification as gunshot residue[18].

The forensic science sector is necessarily cautious to incorporate novel instrumental developments for case work, due to requirements to build a substantial evidence base, validation, and factors affecting results interpretation. This solid underpinning and operation to international standards is now recognised as fundamental to using forensic science in court. Nevertheless, there are opportunities to use advances in microscopy in casework, developing intelligence in cases and in researching new and existing ways of evidence gathering.

The UK Government fingerprint sourcebook [82] is an example of the collation of research information to present a clear body of evidence on which to make recommendations and support science in the courtroom. Whilst previously highlighting the limitations of SEM for casework due to small sample size required, high vacuum and coating leading to destruction or damage to the evidence. The most recent edition (February 2018) shows development of use of techniques in the sector including modern stages, environmental SEM and variable pressure, mitigating some of the practitioner concerns and stabilising the position of the technique with a recommendation as an additional technique in the CAST fingermark visualisation manual [51].

Progress in forensics benefits from advances in microscopy, in the earlier section fingerprint evidence is used as an example of a developing forensic research area. Improving biometric detail of the ridge structure, through developing novel formulations for fingermark development for example powders from quantum dots, new solvents, and micronized powders $[26,53,57]$, studying interactions on complex surfaces and between sequential processes $[51,54,55]$. A separate area seeks to gain also additional information from the suspect, such as gender and drug use to add to the suspect profile $[71,72,74,77]$ or to improve understanding of the forensic scene or timeline $[54,68,69,75,76]$.

Fingerprints, ballistics, etymology, and many other forensic evidence types are subject to increasing levels of research and development highlighting the potential of advanced microscopy methods for crime scene intelligence and evidence. 
[1] Pieri, M., Maldonado, A.L., Ros, M.M., Massoni, F., Ricci, S., Vacchiano, G. Postmortem morphological alterations of human peripheral nerve (2017) Australian Journal of Forensic Sciences, pp. 1-8. Article in Press

[2] Sanit, S., Sukontason, K., Kurahashi, H., Tomberlin, J.K., Wannasan, A., Kraisittipanit, R., Sukontason, K.L.Morphology of immature stages of blow fly, Lucilia sinensis Aubertin (Diptera: Calliphoridae), a potential species of forensic importance (2017) Acta Tropica, 176, pp. 395-401.

[3] Sontigun, N., Sanit, S., Wannasan, A., Sukontason, K., Amendt, J., Yasanga, T., Sukontason, K.L. Ultrastructure of male genitalia of blow flies (Diptera: Calliphoridae) of forensic importance (2018) Acta Tropica, 179, pp. 61-80.

[4] Li, W., Zhang, L., Liang, Y., Tong, F., Zhou, Y. Sudden death due to malignant hyperthermia with a mutation of RYR1: autopsy, morphology and genetic analysis (2017) Forensic Science, Medicine, and Pathology, 13 (4), pp. 444-449.

[5] Visonà, S.D., Chen, Y., Bernardi, P., Andrello, L., Osculati, A. Diagnosis of electrocution: The application of scanning electron microscope and energydispersive X-ray spectroscopy in five cases (2018) Forensic Science International, 284, pp. 107-116.

[6] Kinoshita, H., Nishiguchi, M., Ouchi, H., Minami, T., Kubota, A., Utsumi, T., Sakamoto, N., Kashiwagi, N., Shinomiya, K., Tsuboi, H., Hishida, S. The application of a variablepressure scanning electron microscope with energy dispersive $X$-ray microanalyser to the diagnosis of electrocution: A case report (2004) Legal Medicine, 6 (1), pp. 55-60

[7] Norman, D.G., Watson, D.G., Burnett, B., Fenne, P.M., Williams, M.A. The cutting edge - Micro-CT for quantitative toolmark analysis of sharp force trauma to bone (2018) Forensic Science International, 283, pp. 156-172.

[8] MacPhee, N., Savage, A., Noton, N., Beattie, E., Milne, L., Fraser, J. A comparison of penetration and damage caused by different types of arrowheads on loose and tight fit clothing (2017) Science and Justice, . Article in Press. DOI:

10.1016/j.scijus.2017.11.005

[9] Montoriol, R., Guilbeau-Frugier, C., Chantalat, E., Roumiguié, M., Delisle, M.-B., Payré, B., Telmon, N., Savall, F. Detection of glass particles on bone lesions using SEM-EDS (2017) International Journal of Legal Medicine, 131 (5), pp. 1347-1354.

[10] Vermeij, E.J., Zoon, P.D., Chang, S.B.C.G., Keereweer, I., Pieterman, R., Gerretsen, R.R.R. Analysis of microtraces in invasive traumas using SEM/EDS (2012) Forensic Science International, 214 (1-3), pp. 96-104

[11] Zhao, J., Liu, C., Bardeesi, A.S.A., Wu, Y., Ma, Y., Hu, S., Shi, H., Cheng, J. The Diagnostic Value of Quantitative Assessment of Diatom Test for Drowning: An Analysis of 128 Water-related Death Cases using Microwave Digestion-Vacuum Filtration-Automated Scanning Electron Microscopy (2017) Journal of Forensic Sciences, 62 (6), pp. 1638-1642.

[12] G. M. Wolten, R. S. Nesbitt, A. R. Calloway, G. L. Loper, and P. F. Jones Final Report on Particle Analysis for Gunshot Residue Detection US Department of Justice (1977) Aerospace Report No. ATR-77(7915)-3 

originating from a Luger $9 \mathrm{~mm}$ ammunition in the vicinity of the shooting gun (2009) Forensic Science International 183: 33-44

[14] Macdonald, L.M., Singh, B.K., Thomas, N., Brewer, M.J., Campbell, C.D. and Dawson, L.A. (2008), Microbial DNA profiling by multiplex terminal restriction fragment length polymorphism for forensic comparison of soil and the influence of sample condition. Journal of Applied Microbiology, 105: 813-821.

doi:10.1111/j.1365-2672.2008.03819.x

[15] Konopinski, D.I., Hudziak, S., Morgan, R.M., Bull, P.A., Kenyon, A.J. Investigation of quartz grain surface textures by atomic force microscopy for forensic analysis(2012) Forensic Science International, 223 (1-3), pp. 245-255

[16] Butterworth A, German B, Morgans D, Scaplehorn A (1974) Report on an Investigation into the Trace Elements Present in vehicle Headlamp and auxillary lamp glasses J. Foren. Sci. Soc. 14 p41-45 DOI: 10.1016/S0015-7368(74)70850-7

[17] Arouca, A.M., Lucena, M.A.M., Rossiter, R.J., Talhavini, M., Weber, I.T. Use of luminescent gunshot residues markers in forensic context-Part II (2017) Forensic Science International, 281, pp. 161-170.

[18] Brożek-Mucha, Z. Trends in analysis of gunshot residue for forensic purposes (2017) Analytical and Bioanalytical Chemistry, 409 (25), pp. 5803-5811.

[19] L. Geddes Forensic evidence goes on trial (2009) New Sci. 201:2697 6

[20] The Innocence Project -Keith Allen Harward, available at http://www.innocenceproject.org/cases/keith-allen-harward/ [accessed 22/10/2017]

[21] Michigan Law, National Registry of Exonerations, available at https://www.law.umich.edu/special/exoneration/ [accessed 12/06/2017]

[22] H T Edwards (2014) First public meeting of the National Commission of Forensic Science, available at http://docplayer.net/10750449-First-public-meetingnational-commission-on-forensic-science.html [accessed 24/02/2018]

[23] US Department of Commerce (2017) National Commission on Forensic Science: reflecting back, Looking toward the future, available at https://www.justice.gov/archives/ncfs/page/file/959356/download [accessed 24/02/2018]

[24] A. Rennison, Does quality matter? Lund Lecture of the British Academy of Forensic Sciences, 2010 UK.

[25] B.J. Jones “Nano Fingerprints: Gathering Intelligence" Mater. Today 14 (2011) 567

[26] R.P. Downham, V.G. Sears, L. Hussey, Boon-Seang Chu, B.J. Jones Fingermark visualisation with iron oxide powder suspension: the variable effectiveness of iron (II/III) oxide powders, and Tween 20 as an alternative to Triton X-100 (2018) Forensic Science International, submitted 
[27] Li, F., Liu, S., Qi, R., Li, H., Cui, T. Effective visualization of latent fingerprints with red fluorescent La2(MoO4)3:Eu3+ microcrystals (2017) Journal of Alloys and Compounds, 727, pp. 919-924.

[28] Locard, E. Enquête criminelle et les méthodes scientifiques. Paris : Ernest Flammarion, 1920

[29] Andrea Martiny, Andrea P.C. Campos, Marcia S. Sader, Maj André L. Pinto, $\mathrm{SEM} / \mathrm{EDS}$ analysis and characterization of gunshot residues from Brazilian lead-free ammunition Forensic Sci. Intl. 177 (2008) e9-e17

[30] T Jalanti, P Henchoz, A Galluser, MS Bonafanti Science \& Justice 39 (1999) 4852

[31] Neri, M., Turillazzi, E., Riezzo, I., Fineschi, V. The determination of firing distance applying a microscopic quantitative method and confocal laser scanning microscopy for detection of gunshot residue particles (2007) International Journal of Legal Medicine, 121 (4), pp. 287-292.

[32] Kilty JW. Activity after shooting and its effect on the retention of primer GSR. Journal of Forensic Sciences 1975; 20(2): 219-230

[33] Elspeth Lindsay, Michael J. McVicar, Robert V. Gerard, E. Dale Randall\& Jenny Pearson (2011) Passive Exposure and Persistence of Gunshot Residue (GSR) on Bystanders to a Shooting: Comparison of Shooter and Bystander Exposure to GSR, Canadian Society of Forensic Science Journal, 44:3, 89-96

[34] Molina, D K; Martinez, M; Garcia, James; DiMaio, Vincent American Journal of Forensic Medicine \& Pathology 28 (2007) 187-90 doi:

10.1097/PAF.0b013e31806195e1

[35] Bueno, J., Sikirzhytski, V., Lednev, I.K. Attenuated total reflectance-FT-IR spectroscopy for gunshot residue analysis: Potential for ammunition determination (2013) Analytical Chemistry, 85 (15), pp. 7287-7294

[36] Mou Y, Lakadwar J, Rabalais JW, Evaluation of Shooting Distance by AFM and FTIR/ATR Analysis of GSR , J Forensic Sci 2008; 53:1381-6

[37] BJ Jones Commentary on Evaluation of Shooting Distance by AFM and FTIR/ATR Analysis of GSR Mou Y, Lakadwar J, Rabalais JW, J Forensic Sci 2008; 53:1381-6 Journal of Forensic Sciences 54 (2009) 502

[38] Joly, A., Smargiassi, A., Kosatsky, T., Fournier, M., Dabek-Zlotorzynska, E., Celo, V., Mathieu, D., Servranckx, R., D'amours, R., Malo, A., Brook, J. Characterisation of particulate exposure during fireworks displays (2010) Atmospheric Environment, 44 (34), pp. 4325-4329.

[39] Jackson G, Aitken C, Roberts P (n.d.) Case Assessment and Interpretation of Expert Evidence Royal Statistical Society

[40] Berendes, A., Neimke, D., Schumacher, R. and Barth, M. (2006), A Versatile Technique for the Investigation of Gunshot Residue Patterns on Fabrics and Other Surfaces: m-XRF. Journal of Forensic Sciences, 51: 1085-1090. 
[41] Huda, Z., Shi, K.W. \& Bulpett, R. J Fail. Anal. and Preven. (2009) 9: 305. https://doi.org/10.1007/s11668-009-9260-z

[42] BJ Jones University Challenge: The opportunities for collaboration between industry and academia are now too big to ignore Engineering and Technology 5:9 (2010) 55

[43] Bari, K., Rolfe, A., Christofi, A., Mazzuca, C., Sudhakar, K.V. Forensic investigation of a failed connecting rod from a motorcycle engine (2017) Case Studies in Engineering Failure Analysis, 9, pp. 9-16

[44] S. P. Gurden, V. F. Monteiro, E. Longo \& M. M. C. Ferreira Quantitative analysis and classification of AFM images of human hair Journal of Microscopy, Vol. 215, Pt 1 July 2004, pp. 13-23

[45] C. Wald "Forensic Science: the Soil Sleuth" Nature 520 (2015) 422-4

[46] Garner GE, Fontan CR, Hobson DW (1975) Visualization of fingerprints in the scanning electron microscope J. Foren. Sci. Soc. 15 pp281-288 DOI: 10.1016/S00157368(75)71000-9

[47] T. Kent "Water content of latent fingerprints-dispelling the myth" Forensic Sci. Int., 266 (2016)134-138

[48] Cadd, S., Islam, M., Manson, P., Bleay, S. Fingerprint composition and aging: A literature review (2015) Science and Justice, 55 (4), pp. 219-238

[49] Nicholas J. Bright, Terry R. Willson, Daniel J. Driscoll, Subrayal M. Reddy, Roger P. Webb, Stephen. Bleay, Neil I. Ward, Karen J. Kirkby, Melanie J. Bailey (2013) Chemical changes exhibited by latent fingerprints after exposure to vacuum conditions Forensic Science International, 230, 81

[50] BJ Jones, R Downham, VG Sears (2012) Nanoscale analysis of the interaction between cyanoacrylate and vacuum metal deposition in the development of latent fingerprints on LDPE Journal of Forensic Sciences 57196

[51] Bandey, H. L., Ed. Fingermark Visualisation Manual; Home Office Centre for Applied Science and Technology (CAST): Sandridge, U.K., 2014

[52] Richardson, M (2008) HOSDB placement student project report

[53] BJ Jones, AJ Reynolds, M Richardson, VG Sears (2010) Nano-scale composition of commercial white powders for development of latent fingerprints on adhesives Science and Justice $\mathbf{5 0} 150$

[54] C Au, H Jackson-Smith, I Quinones, BJ Jones, B Daniel (2011) Wet powder suspensions as an additional technique for the enhancement of bloodied marks Forensic Science International 20413

[55] SR Bacon, JJ Ojeda, R Downham, VG Sears, BJ Jones (2013) The effects of polymer pigmentation on fingermark development techniques Journal of Forensic Sciences 581486 
[56] BJ Jones, R Downham, VG Sears (2010) Effect of substrate surface topography on forensic development of latent fingerprints with iron oxide powder suspension Surface and Interface Analysis 42438

[57] OP Jasuja, GD Singh, GS Sodhi, "Small particle reagents: Development of fluorescent variant" Science and Justice 48 (2008) 141-145

[58] GS Sodhi, J Kaur "Unconventional reagents for detecting latent fingerprints: A review" Journal of Forensic Medicine and Toxicology 19 (2002) 18-20

[59] PK Shahi, P Singh, AK Singh, SK Singh, SB Rai, R Prakash “A strategy to achieve efficient dual-mode luminescence in lanthanide-based magnetic hybrid nanostructure and its demonstration for the detection of latent fingerprints" Journal of Colloid and Interface Science 491 (2017) 199-206.

[60] M Wang, Y Zhu, C Mao "Synthesis of NIR-Responsive NaYF4:Yb,Er Upconversion Fluorescent Nanoparticles Using an Optimized Solvothermal Method and Their Applications in Enhanced Development of Latent Fingerprints on Various Smooth Substrates" Langmuir 31 (2015) 7084-7090

[61] Farrugia, K.J., Fraser, J., Friel, L., Adams, D., Attard-Montalto, N., Deacon, P.A comparison between atmospheric/humidity and vacuum cyanoacrylate fuming of latent fingermarks (2015) Forensic Science International, 257, pp. 54-70.

[62] Lam, R., Wilkinson, D., Tse, T., Pynn, B. Recommended protocols for fingerprint detection on Canadian polymer banknotes - Part I: Chemical development (2014) Journal of Forensic Identification, 64 (4), pp. 375-401.

[63] RM Sapstead, N Corden, AR Hillman "Latent fingerprint enhancement via conducting electrochromic copolymer films of pyrrole and 3,4ethylenedioxythiophene on stainless steel" Electrochemica Acta 162 (2015) 119-128

[64] J.W. Cammidge, K.T. Popov, J. O’Hara, K. Farrugia and B.J.Jones Development of latent fingerprints on Scottish Polymer Banknotes Sci. Justice (2018) submitted

[65] A J. Goddard, A. R Hillman, and J W. Bond, "High Resolution Imaging of Latent Fingerprints by Localized Corrosion on Brass Surfaces" J Forensic Sci 2009 doi: 10.1111/j.1556-4029.2009.01217.x

[66] S. Kasas, A Khanmy-Vital, G. Dietler "Examination of line crossings by atomic force microscopy" Forensic Sci Intl 119 (2001) 290-298

[67] GS Watson and JA Watson "Potential Applications of Scanning Probe Microscopy in Forensic Science" J. Phys.: Conf. Ser. 61 (2007) 1251

[68] N Attard Montalto, JJ Ojeda, BJ Jones Determining the order of deposition of natural latent fingerprints and laser printed ink using chemical mapping with secondary ion mass spectrometry. Science \& Justice 53 (2013) 2

[69] N Attard Montalto, JJ Ojeda, A Reynolds, L Doodkorte, M de Puit, M Ismail, M Bailey, BJ Jones Determining the of the order of deposition of natural fingermarks and ink on paper using secondary ion mass spectrometry Analyst 139 (2014) 4641. 
[70] Bright, N.J., Webb, R.P., Bleay, S., Hinder, S., Ward, N.I., Watts, J.F., Kirkby, K.J., Bailey, M.J.Determination of the deposition order of overlapping latent fingerprints and inks using secondary ion mass spectrometry(2012) Analytical Chemistry, 84 (9), pp. 4083-4087

[71] S. Francese, R.Bradshaw, L.S.Ferguson, R. Wolstenholme, M.R. Clench, S Bleay "Beyond the ridge pattern: Multi-informative analysis of latent fingermarks by MALDI mass spectrometry" Analyst 138 (2013) 4215-4228

[72] Bailey, M.J., Bright, N.J., Croxton, R.S., Francese, S., Ferguson, L.S., Hinder, S., Jickells, S., Jones, B.J., Jones, B.N., Kazarian, S.G., Ojeda, J.J., Webb, R.P., Wolstenholme, R., Bleay, S. "Chemical characterization of latent fingerprints by matrix-assisted laser desorption ionization, time-of-flight secondary ion mass spectrometry, mega electron volt secondary mass spectrometry, gas chromatography/mass spectrometry, X-ray photoelectron spectroscopy, and attenuated total reflection Fourier transform infrared spectroscopic imaging: An intercomparison" Analytical Chemistry 84 (2012) 8514-8523.

[73] MJ West, MJ Went "The spectroscopic detection of drugs of abuse in fingerprints after development with powders and recovery with adhesive lifter" Spectrochimica Acta - Part A: Molecular and Biomolecular Spectroscopy 71 (2009) 1984-1988

[74] Francese, S., Bradshaw, R., Denison, N. An update on MALDI mass spectrometry based technology for the analysis of fingermarks-stepping into operational deployment (2017) Analyst, 142 (14), pp. 2518-2546.

[75] BN Dorakumbura, T Becker, SW Lewis Nanomechanical mapping of latent fingermarks: A preliminary investigation into the changes in surface interactions and topography over time Forensic Science International 267 (2016) 16-24

[76] KT Popov, VG Sears, BJ Jones "Migration of latent fingermarks on non-porous surfaces: Observation technique and nanoscale variations" Forensic Science International 275 (2017) 44-56

[77] Popov, K.T., Sears, V.G., Jones, B.J. Nanoscale topography of latent fingermarks: variation of material migration with donor (2018) Forensic Science International submitted

[78] De Nardi, C., Desplats, R., Perdu, P., Beaudoin, F., Gauffier, J.-L. Oxide charge measurements in EEPROM devices (2005) Microelectronics Reliability, 45 (9-11), pp. 1514-1519.

[79] BJ Jones and AJ Kenyon Retention of data in heat-damaged SIM cards and potential recovery methods Forensic Science International 177 (2008) 42

[80] AK Adya and E Canetta, Atomic force microscopic investigation of commercial pressure sensitive adhesives for forensic analysis Forensic Science International 210 (2011) 16 
[81] Strasser, S., Zink, A., Kada, G., Hinterdorfer, P., Peschel, O., Heckl, W.M., Nerlich, A.G., Thalhammer, S. Age determination of blood spots in forensic medicine by force spectroscopy (2007) Forensic Science International, 170 (1), pp. 8-14.

[82] Stephen Bleay, Vaughn Sears, Rory Downham, Helen Bandey, Andrew Gibson, Valerie Bowman, Lesley Fitzgerald, Tomasz Ciuksza, Jona Ramadani, Chris Selway Fingerprint Source Book v2.0 ISBN 978-1-78655-434-5, CAST publication 08117 available at https://www.gov.uk/government/publications/fingerprint-source-bookv2 [Accessed 7th March 2018] 
Microscopy in Forensic Science BJ Jones in Springer Handbook of Microscopy eds. J.C.H Spence and P. Hawkes Springer, Heidelberg (2019) Chapter In Press

Pre Proof Version

\section{Acknowledgements}

Thanks to Mrs Isobel Stewart MRSC CChem for helpful comments and to Insp. Dennis Gentles (Retd.) for setting crime scene. 